\title{
AVALIAÇÃO DO CONHECIMENTO DE ALUNOS DO ENSINO MÉDIO SOBRE O DESTINO DOS RESÍDUOS SÓLIDOS DOMÉSTICOS
}

Everton Josué Manica ${ }^{1}$

Liana Johann ${ }^{2}$

Resumo: A Educação Ambiental tem usado como ferramenta principal a sensibilização dos alunos para promover atividades voltadas à minimização da produção dos resíduos sólidos domésticos e trabalhar de forma correta o descarte dos mesmos. Com isso, o presente artigo teve como objetivo analisar o conhecimento dos alunos do Ensino Médio de uma escola do Vale do Taquari, Rio Grande do Sul, Brasil, sobre o destino dos resíduos sólidos domésticos através da aplicação de um questionário. Pode-se afirmar, com as respostas obtidas, que os estudantes possuem pouco conhecimento sobre resíduos sólidos domésticos, mas ao mesmo tempo os estudantes do Ensino Médio estão preocupados com o destino final e a melhor forma de tratamento dos resíduos sólidos domésticos produzidos em suas casas.

Palavras-chave: Destinação; Educação Ambiental; Resíduos Sólidos Domésticos; Separação.

${ }^{1}$ Graduando em Ciências Biológicas - Licenciatura. Universidade do Vale do Taquari - Univates, Lajeado/RS. E-mail: everton.manica@universo.univates.br

2 Professora do Curso de Ciências Biológicas - Licenciatura e Bacharelado. Doutora em Zoologia. Universidade do Vale do Taquari - Univates, Lajeado/RS. E-mail: liana@univates.br

Revbea, São Paulo, V. 14, № 4: 74-86, 2019. 


\section{Introdução}

Os resíduos sólidos domésticos são vistos com desprezo pelo ser humano. Representam restos de atividades produzidas pela população, resíduos indesejados que vão se acumulando por anos e anos. Este processo de acúmulo favorece a proliferação de microrganismos patogênicos associados a dejetos e fluidos corporais, assim como o descarte de restos de alimentos orgânicos e resíduos inorgânicos (VELOSO, 2007).

A condução dos estudantes para a percepção desse problema no cotidiano, através da observação do que é produzido nos domicílios, é a maneira mais simples e prática para trabalhar. Pode-se definir que resíduos sólidos domésticos são classificados em orgânicos e inorgânicos. Os materiais orgânicos são os restos de comidas, frutas, verduras, vegetais entre outros. Já os materiais inorgânicos são vidro, plástico, papel, metais e papel higiênico contaminado, esses sempre sendo separados em recipientes com corres diferentes (BALDISSARELLIET et al., 2009)

$\mathrm{Na}$ idade média os resíduos provenientes do ser humano estavam associados à sua qualidade de vida e consumos excessivos, como desperdício de comidas e animais mortos, onde seus restos e carcaças ficavam jogados no mesmo espaço ocupado pelo homem. No século XIV, a população começou a se preocupar com o excesso de resíduos produzidos pela humanidade, pois esses excessos já estavam trazendo problemas à saúde das pessoas, como o surgimento de pestes e doenças (VELOSO, 2007).

No Brasil, os municípios ainda não possuem os recursos necessários para combater os problemas ligados à gestão de resíduos sólidos domésticos. Muitas vezes é ignorada a ideia de buscar ajuda ou parcerias através de segmentos que deveriam ser envolvidos na gestão ambiental, com intuito de buscar alternativas e implantação de soluções com o apoio delas. Os resíduos sólidos domésticos são descartados em lixões a céu aberto ou em vazadouros sem qualquer controle ambiental ou sanitário e nem mesmo fiscalizados. Assim, comprometendo o ambiente, gerando montanhas de entulhos que além de degradar a paisagem e deixar mau cheiro, geram graves problemas à saúde pública e ao meio ambiente. É responsabilidade das prefeituras municipais e da comunidade local o gerenciamento dos resíduos sólidos domésticos, porém poucos possuem um sistema de coleta que os trate e destine de maneira correta (MMA, 2019). IBGE (2017) revela que 64\% das cidades brasileiras não dão um destino correto para os resíduos sólidos domésticos, encaminhando direto para lixões a céu aberto, $14 \%$ dos municípios possuem aterro sanitário e apenas $18 \%$ possuem aterros controlados como destino.

O destino incorreto dos resíduos sólidos domésticos, principalmente em grandes cidades pode gerar diversos problemas sociais, econômicos e principalmente ambientais. Além disso, os resíduos podem favorecer a proliferação de insetos e outras pragas que podem ser vetores de inúmeras doenças. Esses problemas poderiam ser diminuídos se houvesse 
conscientização por parte da população, buscando diminuir seus resíduos produzidos atualmente (MARODIN; BARBA; MORAIS, 2004).

Os impactos ambientais negativos gerados pelo destino inadequado dos resíduos sólidos domésticos têm como causa principal a ampliação das áreas urbanas (MUCELIM; BELLINI 2008). Esses impactos estão relacionados com a cultura da população, seus hábitos de consumo de produtos industrializados e uso da água. Dentro desses aspectos culturais se desenvolvem costumes que irão determinar a produção de resíduos sólidos domésticos e a forma de tratamento desses, ou como serão distribuídos no ambiente. Esses aspectos afetam principalmente a região urbana, mas podem também afetar áreas não urbanizadas. Entre os resíduos produzidos nas áreas urbanas estão os resíduos comerciais, domésticos, e resíduos sólidos industriais, constituídos de várias materiais e substâncias que podem gerar grandes riscos ao ser humano e outros seres (GOUVEIA; PRADO, 2010).

Tais impactos causarão alterações ambientais, físicas e biológicas que, no decorrer do tempo, modificarão a paisagem e comprometerão os ecossistemas. Essas condições citadas acima não são consideradas naturais, mas sim antropológicas. Faz-se necessário lembrar que as alterações ambientais têm diferentes causas, como afirma Fernandez (2004), podendo elas ser inumeráveis e provenientes de formas naturais. Contudo, sabe-se de maneira evidente que o desenvolvimento das culturas de comunidades contemporâneas tem contribuído na aceleração dessas transformações como consequência dos avanços tecnológicos e da intensidade do consumo (MUCELIM; BELLINI, 2008).

Vale ressaltar que as alterações ambientais, a diminuição dos recursos naturais e o aumento dos resíduos sólidos domiciliares fez com que o homem começasse a se preocupar com medidas prévias para combater esse aumento drástico de resíduos. Por isso, o ser humano teve a ideia de começar a reaproveitar os materiais descartados através da reciclagem. A reciclagem nada mais é do que recuperar e reaproveitar materiais que não possuem mais serventia (RIBEIRO; LIMA, 2000).

$\mathrm{O}$ ato de reciclar tem o significado de refazer o ciclo de vida do produto, permitindo trazê-lo novamente à origem de outra forma. Os materiais que não se degradam rapidamente podem ser reaproveitados através do reprocessamento. A prática de reciclar tem como objetivo reduzir a quantidade de resíduos sólidos domésticos, bem como diminuir os gastos excessivos de matéria prima e de energia. Isso pode despertar o interesse pela adoção de hábitos que promovam a redução da degradação do meio ambiente e do uso excessivo de materiais desnecessários para sua sobrevivência (SILVA, 2005). Segundo MMA (2018), a reciclagem tem grandes fins lucrativos, além de proporcionar um equilíbrio ecológico. São vários os países que estão investindo fortemente em tecnologias voltadas a reciclagem, pois para cada tipo de material a um modo correto de reciclar. Para que esses materiais sejam devidamente separados é necessário 
que haja uma colaboração da sociedade, com a coleta seletiva dos resíduos sólidos, onde desde casa as pessoas separem e classificam os mesmos.

A reciclagem é uma das melhores alternativas em relação à destinação dos resíduos sólidos domésticos. Se os resíduos forem tratados de maneira correta e com o auxílio da coleta seletiva podem gerar empregos dignos e renda a mais para as comunidades. Vale ainda ressaltar que a coleta seletiva é o modo mais empregado nos centros de triagem, pois a reciclagem consiste em separar os materiais que podem ser reaproveitados, na própria fonte geradora que são os domicílios (CORTEZ, 2002).

Nesse sentido, a Educação Ambiental tem um papel fundamental na conscientização da população sobre a importância de reduzir e reciclar os resíduos sólidos domésticos. A Educação Ambiental nada mais é do que a dimensão da educação que tem por objetivo trabalhar em sala de aula a melhor maneira de estabelecer conexões dos alunos com o meio ambiente, mostrando a importância de preservar o meio através do desenvolvimento de habilidades, atitudes e competências voltadas para a conservação do espaço. Também procura trabalhar de forma plena a prática social e a ética ambiental (MMA, 2019).

Nos últimos anos a Educação Ambiental tem sido ferramenta essencial para colaborar nas transformações socioambientais. As escolas foram um dos primeiros lugares a se aplicar esse tipo de projeto, tendo em vista a responsabilidade de melhorar a qualidade de vida das pessoas e a infraestrutura das famílias através de informações que contribuam para a conscientização da população. Por fim, é importante que o espaço escolar esteja pronto para receber ações voltadas à Educação Ambiental e que os professores realmente trabalhem o assunto com os discentes, pois somente assim formarão pessoas com conduta e responsabilidade em relação ao meio ambiente. Isso é importante, pois além dos estudantes se conscientizarem, levarão essas informações a suas famílias. Também é importante ressaltar que é através desses projetos que as escolas estarão passando o conhecimento de uma maneira ampla, abordando vários temas, entre eles os temas resíduos sólidos e reciclagem, temas que estão relacionados ao dia a dia das crianças (SEGURA, 2001).

A Educação Ambiental deve trabalhar com ênfase o desenvolvimento sustentável, a fim de capacitar a população sobre o assunto abordando questões ambientais necessárias para que possam avaliar e tomar as medidas necessárias sobre o conhecimento dos jovens (TENERELLI; SILVA; PAIVA 2006). É importante incentivar os alunos e a comunidade local a trabalharem os problemas presentes em suas comunidades. Buscando mostrar, na prática, a maneira correta que os jovens devem trabalhar os resíduos, começando por evitar o consumo desnecessário, comprando produtos de empresas que se preocupem com o meio ambiente além de separar os materiais entre orgânicos e inorgânicos em sua fonte de produção (SILVA, 2010). 
Uma das maneiras mais simples e práticas para o início do processo de separação dos resíduos sólidos é implantação na escola e nas casas dos alunos. Outras ações que podem ser desenvolvidas são palestras para conscientização, mostrando os benefícios da correta separação e destinação dos resíduos sólidos domésticos. Os malefícios também devem ser expostos aos estudantes, como todos os prejuízos oriundos da má destinação desses resíduos. É esperado que os alunos saibam a maneira correta de separação dos resíduos sólidos domésticos entre orgânicos e inorgânicos facilitando o trabalho dos coletores nos centros de triagens. Conforme salienta Fiurini e Klein (2016), os alunos devem saber que é necessário diminuir a produção dos resíduos sólidos domésticos, além de realizar a separação deles entre orgânicos e inorgânicos, para melhorar a coleta seletiva na comunidade e conscientizar as pessoas para manter a escola e a cidade limpas.

O objetivo desse trabalho foi avaliar o nível de conhecimento dos alunos do Ensino Médio, de uma escola da $3^{\text {a }}$ Coordenadoria de Educação do Rio Grande do Sul (RS), sobre os resíduos sólidos domésticos, a separação e a destinação final dos resíduos.

\section{Material e Métodos}

Essa pesquisa foi realizada a partir da aplicação de um questionário para as turmas do Ensino Médio de uma escola do Vale do Taquari, RS. A aplicação do questionário foi realizada, após autorização da direção da escola, no mês de abril de 2019. Foram entrevistados cinquenta e quatro alunos do Ensino Médio.

A escola situa-se na zona urbana de um município do interior do RS, pertencente à $3^{\underline{a}}$ Coordenadoria de Educação. O município disponibiliza transporte escolar para todos os estudantes do interior. A escola atende alunos provenientes da zona rural, na grande maioria filhos de agricultores e ou que recebem auxílio governamental (bolsa família) e alunos da zona urbana, cujas famílias exercem funções diversificadas (funcionários públicos, autônomos, comerciantes).

A escola possui autorização para atender Ensino Fundamental e Ensino Médio. Séries iniciais no turno da tarde e o Ensino Médio no turno da manhã, totalizando 171 alunos, 18 professores, duas bibliotecárias, duas coordenadoras pedagógicas, a diretora, vice-diretora e os demais atuando como regentes de classe, 2 funcionárias que trabalham na cozinha e na limpeza. Podemos perceber que na escola não existe a separação de resíduos sólidos, apenas são dispostos dentro de lixeiras confeccionadas a partir de galões de óleo. Uma composteira está sendo construída para a destinação dos resíduos sólidos orgânicos.

No município não existe até o momento campanhas voltadas a separação dos resíduos sólidos domésticos, são todos depositados em um mesmo espaço esperando até o dia da coleta. $\mathrm{Na}$ área central da cidade, o caminhão de resíduos passa duas vezes por semana, nas segundas e quintas-feiras pela 
parte da manhã. Já nas áreas do interior do município, o caminhão passa apenas de quinze em quinze dias. Todos os materiais são recolhidos por uma empresa terceirizada responsabilizada por encaminhar os resíduos para um aterro sanitário localizado na cidade de Candiota, RS.

Para tornar possível a aplicação do questionário foi necessário ter um primeiro contato com a direção da escola. Para isso foi realizada uma breve apresentação pessoal. Após ser devidamente apresentado, verificou-se a possibilidade de aplicar um questionário aos alunos do Ensino Médio sobre resíduos sólidos domésticos. Explicou-se que o questionário visava avaliar o conhecimento dos jovens sobre o assunto, através de questões objetivas, e questões abertas. Após autorização da direção, agendou-se uma nova data para aplicação do questionário. No dia da aplicação do questionário, direção e professor titular estavam presentes. O trabalho foi apresentado aos alunos e posteriormente os questionários foram respondidos.

As respostas obtidas foram tabuladas em planilha de Excel, e os percentuais foram calculados.

\section{Resultados e discussão}

Foram entrevistados 54 alunos do Ensino Médio. Do total de estudantes, $59,3 \%$ eram do sexo feminino e $40,7 \%$, do sexo masculino.

Quando questionados sobre o que é um resíduo sólido doméstico 17,7\% dos estudantes responderam que são restos de alimentos, $14,6 \%$ responderam que são plásticos, vidros, ferro e alumínio, $1 \%$ respondeu que são objetos velhos e 22,9\% responderam que todos esses itens citados são resíduos sólidos domésticos. Conforme já citado na introdução os resíduos sólidos domésticos são aqueles produzidos nos domicílios, como plásticos, metais, vidros, restos de alimentos, matéria que é varrida para fora da casa, resíduos sanitários, papelão e trapos velhos de roupas. Também podemos citar materiais mais perigosos como é o caso de pilhas, medicamentos vencidos, lâmpadas, querosene e solventes (BALDISSARELLIET et al., 2009). As respostas dadas pelos alunos indicam que apenas $22,9 \%$ dos estudantes realmente compreendem o que são resíduos sólidos domésticos. No entanto, as outras opções não estão totalmente erradas.

O que sua família faz com os resíduos sólidos domésticos? Dos alunos entrevistados, $64,8 \%$ citaram que colocam nas lixeiras para o caminhão recolher, $20,4 \%$ dão para os porcos, quando os resíduos são orgânicos, $7,4 \%$ responderam que jogam na propriedade, $5,6 \%$ escreveram que seus pais colocam fogo nos resíduos e 1,9 responderam que enterram os mesmos na propriedade. Em seguida foi levantada a questão: Em sua casa, você costuma separar os resíduos sólidos domésticos? 53,7\% responderam que não separam, pois não tem necessidade e $46,3 \%$ responderam que sim, separam os resíduos entre orgânicos e inorgânicos. Também foi perguntado se é importante separar os resíduos sólidos domésticos? 94,4\% responderam que sim e 5,6\% dos alunos

revista brasileira educação ambiental 
responderam que não. Apesar de mais de $50 \%$ dos jovens responderem que não separam os resíduos sólidos domésticos em sua casa, podemos perceber que os alunos não têm um conhecimento muito profundo sobre o assunto. Contudo é possível observar que eles ficam preocupados com o destino final dos resíduos, buscando a melhor forma para trabalhar e tratar esses rejeitos. Lima (2001) diz que a melhor forma de dar um bom destino aos resíduos sólidos domésticos é poder dar como destino final a separação em uma central de triagem, local onde os materiais são separados por setores e, o que não pode ser reutilizado, tem como destino final os aterros sanitários e o restante dos materiais é reciclado.

Também foi perguntado aos alunos se existem caminhões da prefeitura que passam recolhendo os resíduos sólidos domésticos em suas casas. Dentre os estudantes, $90,7 \%$ responderam que sim e apenas $9,3 \%$ responderam que não tem recolhimento de resíduos sólidos domésticos em suas casas. Também foi questionado com qual frequência o caminhão passa para realizar a coleta dos resíduos sólidos domésticos. $53,7 \%$ responderam que o caminhão passa apenas uma vez por mês, 40,7\% responderam que o caminhão passa duas vezes por semana e 5,6\% responderam que o caminhão passa de quinze em quinze dias. Essas respostas estão associadas com o local que os jovens residem no município, quando citam que é de quinze em quinze dias é em função dos jovens serem do interior do município. E quando falam que o caminhão passa duas vezes por semana é em função dos adolescentes morarem no centro da cidade. É possível destacar que o simples fato de pré-estabelecer a coleta dos resíduos sólidos domésticos, com os dias e a frequência do recolhimento, faz com que a comunidade participe das ações voltadas ao gerenciamento dos resíduos (SIMONETTO; BORENSTEIN, 2004). A constituição de 1988 deixa claro que os municípios são os responsáveis pelo saneamento básico, pela proteção do meio ambiente, por combater a poluição e diminuir os resíduos sólidos produzidos pela população, colocando em prática ações de Educação Ambiental com a comunidade. A gestão de limpeza urbana e o recolhimento dos resíduos sólidos domésticos também são de responsabilidade dos órgãos municipais.

Quando questionados sobre o destino dos resíduos sólidos domésticos produzidos em sua cidade, $48,1 \%$ responderam que os resíduos sólidos domésticos vão para um aterro sanitário presente na própria cidade, 38,9\% responderam que os resíduos vão para um lixão a céu aberto, $7,4 \%$ responderam que vão para alguma usina de compostagem e reciclagem e 5,6\% responderam que vão direto para terrenos baldios. A resposta dos participantes demonstra total desconhecimento sobre o que de fato acontece com os resíduos sólidos nesse município, já que, segundo dados coletados na Secretaria Municipal do Meio Ambiente, os resíduos sólidos domésticos produzidos pela população são recolhidos por uma empresa terceirizada. Esses resíduos são coletados e encaminhados a um aterro sanitário localizado na cidade de Candiota, RS.

Quando indagados sobre os resíduos sólidos domésticos produzidos em maior quantidade em sua casa, $66,7 \%$ responderam que são os resíduos 
orgânicos, 29,6\% responderam que são os resíduos inorgânicos e apenas 3,7\% classificou como rejeitos. Segundo o MMA (2017), os resíduos sólidos orgânicos são considerados como mais da metade da matéria produzida nas residências do povo Brasileiro. Esses resíduos são constituídos principalmente por restos de alimentos humanos e restos de alimentos de animais.

Seguindo nessa linha, os alunos foram questionados sobre o que as famílias fazem com os resíduos sólidos orgânicos. Do total de estudantes, 48,1\% responderam que dão para os animais, 31,5\% responderam que usam na horta como adubo orgânico, 9,3\% responderam que colocam para o caminhão do lixo levar embora, 3,7\% responderam que queimam os materiais orgânicos, 1,9\% responderam que enterram o material na propriedade e 1,9 responderam que deixam no terreno. Em resumo, $83,4 \%$ dos alunos dizem reutilizar o resíduo orgânico na própria residência. A melhor forma de destinar os resíduos sólidos domésticos orgânicos é a compostagem, tornando a matéria orgânica em adubo, que pode ser utilizado na horta das residências. Os resíduos produzidos em pequenas escalas podem ser trabalhados de forma doméstica mesmo, sem o uso de equipamentos mais sofisticados para dar o resultado que é o adubo. Quando a matéria orgânica está sendo destinada de forma adequada, está evitando gastos desnecessários. Desta forma é evitada a deposição da matéria juntamente com os resíduos inorgânicos, o que poderia acarretar despesas maiores, além de ocupar um espaço desnecessário nos aterros (MMA, 2019).

Com relação aos problemas que os resíduos sólidos domésticos podem causar para o ser humano e ao meio ambiente, $48,1 \%$ responderam que podem acarretar a contaminação do meio ambiente, $20,4 \%$ responderam que poderia causar problemas à saúde humana, 16,7\% responderam que poderia trazer consequências visuais à paisagem, 9,3\% responderam que poderiam causar problemas relacionados com a dengue e $5,6 \%$ responderam que não causa nem um tipo de problema. Os resíduos sólidos domésticos podem gerar problemas ambientais relacionados à saúde pública, contaminação de rios, lençóis freáticos, contaminação do solo, transmissão de doenças, proliferação de vetores, entupimento de bueiros causando alagamentos, além de gerar a poluição visual e trazer odores indesejados (MUCELIN; BELLINI, 2008). Muitas vezes os resíduos sólidos domésticos são jogados em qualquer lugar, sem nenhuma preocupação com os malefícios que ele pode causar ao ambiente e a população (MURATA; FRANÇA, 2014).

Quando se questionou a respeito da análise individual: Você conhece os problemas causados pelos resíduos sólidos domésticos? Onde obteve estas informações? $85,2 \%$ responderam que obtiveram informações através da escola, 9,3\% não responderam e 5,6\% responderam que foi através de programas de televisão. Depois perguntou-se aos alunos: Você já recebeu alguma orientação para separar os resíduos sólidos domésticos produzidos em seu dia a dia? $61,1 \%$ responderam que sim, através da escola e de palestras e $38,9 \%$ responderam que nunca receberam nenhuma orientação de como separar os resíduos sólidos domésticos. 
Podemos perceber que durante a parte do questionário supracitada, os jovens apresentaram em suas respostas um baixo conhecimento sobre 0 assunto trabalhado, porém, mesmo assim, citam a escola como o espaço no qual os mesmos obtêm as melhores informações a respeito dos resíduos sólidos domésticos e os problemas ambientais entrelaçados à sociedade, inerentes ao descarte inadequado dos resíduos sólidos domésticos. Uma boa alternativa para tornar os alunos participativos e que eles possam aprender sobre o gerenciamento de resíduos sólidos domésticos é pela participação em projetos de Educação Ambiental nas escolas. Esses projetos devem ser trabalhados em parceria com técnicas voltadas à realidade desses jovens, possibilitando a intervenção deles, pois assim estarão vinculados com seu cotidiano (CRISOSTIMO, 2011). Neste momento os professores precisam se beneficiar de atividades lúdicas, pois é a melhor forma para os alunos conseguirem se identificar e fixar o aprendizado. É através de jogos, palestras e gincanas que o conhecimento e o prazer por aprender se mesclam e trazem bons resultados (BASTOS; MACEDO; MOREIRA, 2005).

$\mathrm{Na}$ questão, em sua opinião de quem é a responsabilidade pela redução e tratamento dos resíduos sólidos domésticos? $81,5 \%$ dos jovens responderam que é responsabilidade de todos, $14,8 \%$ dos alunos citam que é responsabilidade da prefeitura municipal, 1,9\% comentaram que é responsabilidade dos domicílios e 1,9\% dos alunos não contestaram. Conforme salienta Teixeira (2001), é responsabilidade da prefeitura municipal o manuseio e a destinação correta dos resíduos sólidos domésticos. Esta responsabilidade é assumida pelo Município, pois recebe a contrapartida da comunidade através dos impostos arrecadados. Assim, cabe à Prefeitura a retirada dos resíduos, coleta e transporte deles, bem como sua destinação com tratamento e deposição final. MMA (2019) diz que a Lei oㅜ 12.305/10 institui a Política Nacional de Resíduos Sólidos prevê diminuir e reduzir a geração dos resíduos sólidos produzidos pela população. E para que o objetivo desta lei seja cumprido é de responsabilidade do agente gerador e do órgão público, no caso deste trabalho, é de responsabilidade da prefeitura e da comunidade dar o destino correto para estes resíduos. Também é importante promover hábitos de consumo sustentável, buscando proporcionar um aumento nos produtos recicláveis e da reutilização dos materiais reutilizáveis, pois estes têm um valor econômico muito grande.

Quanto à possibilidade de reduzir a quantidade de resíduos domésticos gerados na sua rotina e como reduzir, $50 \%$ dos alunos responderam que não é possível diminuir a quantidade de resíduos. Complementaram a resposta dizendo que os mesmos são fundamentais e que está muito bom deste jeito para eles, pois não estão sendo afetados, 29,6\% responderam que sim é possível diminuir e reutilizar os resíduos sólidos domésticos, e por fim $20,3 \%$ responderam que sim, é possível diminuir, porém cada um deve fazer sua parte. Nesta questão conseguimos perceber que $49,9 \%$ dos alunos demonstram interesse em buscar alguma maneira para diminuir a quantidade de resíduos sólidos domésticos produzidos. Conforme explica Daminelli e Silva (2009), a melhor forma para se trabalhar os resíduos sólidos domésticos é através dos 
órgãos públicos, que deve apoiar a iniciativa de projetos educacionais na comunidade local, buscando conscientizar a população através de práticas ambientais da gestão de resíduos domésticos. Também devem buscar minimizar os resíduos e valorizar a Educação Ambiental como estratégia para diminuir os impactos causados pelo destino inadequado dos resíduos sólidos domésticos. Soares, Salgueiro e Gazineu (2007) salientam que não existe um modelo préestabelecido para a Educação Ambiental ser trabalhada, pois cada local deve tratar o assunto conforme sua realidade, buscando atingir da melhor e maior forma possível seu público alvo. Também é importante lembrar que é de suma importância sensibilizar a população sobre os problemas que acarretam a má destinação dos resíduos sólidos domésticos.

Para finalizar, ao responder a questão sobre a identificação do destino mais adequado para os resíduos gerados nas residências de seu município, $90,7 \%$ dos alunos responderam que a melhor forma para dar um bom destino aos resíduos sólidos domésticos é deixando que o caminhão do lixo os leve até um aterro sanitário. Os demais não responderam a questão. É através da reutilização que se dá a melhor destinação e a melhor forma para trabalharmos os resíduos sólidos domésticos, buscando reciclar os materiais inorgânicos e realizando a compostagem dos materiais orgânicos. Como deposição final dos resíduos inorgânicos devemos separar os mesmos por categorias buscando aumentar o número da reciclagem de matéria sólida, se beneficiando da educação para o consumo sustentável (MMA 2019).

\section{Considerações finais}

Pode-se afirmar, com as respostas obtidas, que os estudantes possuem pouco conhecimento sobre resíduos sólidos domésticos. É possível observar que mesmo com pouco conhecimento, os estudantes de Ensino Médio estão preocupados com o destino final e a melhor forma de tratamento dos resíduos sólidos domésticos produzidos em suas casas.

Sugere-se que escola e município trabalhem ações ambientais em conjunto. Palestras sobre o assunto, atividades lúcidas, rodas de conversa são uma possibilidade para os estudantes compreenderem e sentirem-se também responsáveis pela geração e destinação dos resíduos sólidos domésticos.

\section{Agradecimentos}

A direção e funcionários da escola por permitirem a aplicação da pesquisa na escola. A Secretaria do Meio Ambiente da cidade por ter fornecido as informações necessárias para tornar possível o desenvolvimento do presente artigo. Este fazendo parte da exigência para obtenção de graduação no curso de Ciências Biológicas Licenciatura. 


\section{Referências}

BALDISSARELLI, A. et. al., Considerando mais o lixo. 2. ed. Florianópolis: Copiart, 2009. Disponível em:< http://www.pmf.sc.gov.br/arquivos/arquivos/pdf/ 29022012 18.45.04.7077a606f3fda0d488e445bd509fb45b.pdf > Acesso em: 03 de jun. 2019.

BASTOS, F. F.; MACEDO, N. S. S.; MOREIRA, N. M. C. P. A Educação Ambiental no curso normal superior do Instituto Superior de Educação de Santo Antonio de Pádua: um estudo de caso. 2005. 51 f. Monografia - Fundação de Apoio à Escola Técnica, Santo Antônio de Pádua, 2005. Disponível em: < file:///C:/Users/HP/Desktop/1437-2890-2-PB\%20(1).pdf> Acesso em:10/11/19.

BURGIERMAN, D. R. A terceira fronteira. Sustentável é pouco: ideias e experiências que vão além do discurso da sustentabilidade, 2010. Disponível em: $\quad<$ https://sustentavelepouco.wordpress.com/2010/07/19/a-terceirafronteira/> Acesso em 29 de jul. 2019.

CORTEZ, A. T. C. Coleta seletiva e reciclagem de resíduos sólidos. In: CAMPOS, J.O., BRAGA, R., CARVALHO, P.F. (org.) Manejo de pressupostos para a gestão ambiental. Rio Claro-SP Laboratório de Planejamento Municipal - DEPLAN. - IGCE - UNESP), 2002.Pág. 41- 48.

CRISOSTIMO, A. L. Educação Ambiental, reciclagem de resíduos sólidos e responsabilidade social: formação de educadores ambientais. Rev. Conexão UEPG, 2011. Disponível em:< http://www.revistas2.uepg.br/index.php/conexao/ article/view/3687> Acesso em: 10 de jun. 2019. Pág.88 - 94.

DAMINELLI, R. M.; SILVA, S. M. Casos de Sucesso na Educação Ambiental. Curitiba: IESDE, 2009. Pg. 56

FERNANDEZ, F. A. S. O poema imperfeito: crônicas de Biologia, conservação da natureza, e seus heróis. 2. ed. Curitiba: UFPR, 2004. Disponível em: <https://www.skoob.com.br/livro/pdf/o-poema-imperfeito/livro: 30702/edicao:47530> Acesso em:

FIURINI, Marcos Aleandro. KLEIN; Tânia Aparecida da Silva. Reflexão sobre a questão do "lixo" no ambiente escolar a partir da metodologia da problematização. Os desafios da escola pública paranaense na perspectiva do professor PDE. Governo do Estado do Paraná - Secretaria da Educação, V. 1. P.01-17, 2016. Disponível em: < http://www.diaadiaeducacao.pr.gov.br/ portals/cadernospde/pdebusca/producoes pde/2016/2016 artigo cien uel ma rcosaleandrofiurini.pdf> Acesso em 16 de jun. de 2019.

GONZATTI, R. Diagnóstico dos resíduos sólidos domésticos do município de Sério/RS com vista à integração consorciada com outros municípios. 2012. 76 f. f. Trabalho de Conclusão de curso - Curso de Engenharia Ambiental, Centro Universitário UNIVATES, Lajeado, 2012. 
GOUVEIA, N.; PRADO, R. R. Riscos à saúde em áreas próximas a aterros de resíduos sólidos urbanos, Revista Saúde Pública, v. 44, n. 5, p. 859-866, 2010. Disponível em:< https://bdpi.usp.br/bitstream/handle/BDPI/9412/art GOUVEIA Riscos a saude em areas proximas a 2010.pdf?sequence $=1>$ Acesso em 29 de mai. 2019

IBGE - Instituto Brasileiro de Geografia e Estatística. Estimativas populacionais para os municípios e para as Unidades da Federação brasileiros em 01.07.2017. Disponível em:< https://ww2.ibge.gov.br/home/ estatistica/populacao/estimativa2017/estimativa dou.shtm>

MARONDIN, V. S.; BARBA, I. S.; MORAIS, G. A. $2^{\circ}$ Congresso Brasileiro de Extensão Universitária, 2004. Anais... Belo Horizonte:UFMG, 2004. Disponível em:<https://www.google.com/search?q=MARODIN, + V.+S.\%3B+BARBA,$+E$.

$\% 3 \mathrm{~B}+\mathrm{MORAIS},+\mathrm{G} .+\mathrm{A} .+2 \% \mathrm{C} 2 \% \mathrm{BA}+$ Congresso+Brasileiro+de+Extens\%C3\%A3 o+Universit\%C3\%A1 ria, $+2004 .+$ Anais...+Belo+Horizonte:UFMG,$+2004 . \& s a=X \&$ ved=0ahUKEwjOp ri3fbiAhUZHbkGHdhUBfoQ7xYILCgA\&biw=1366\&bih=667> Acesso em 02 de jun. 2019.

MINISTÉRIO DIO MEIO AMBIENTE (MMA), Compostagem. 2019 Disponível em: <http://www.mma.gov.br/estruturas/secex consumo/arquivos/composta gem.pdf>

MINISTERIO DO MEIO AMBIENTE (MMA). Conceitos de Educação Ambiental, 2018. Disponível em: <http://www.mma.gov.br/educacaoambiental/politica-de-educacao-ambiental >. Acesso em: 08.nov.2018.

MUCELIN, C. A. BELLINI. M. Lixo e impactos ambientais perceptíveis no ecossistema urbano. VER. Sociedade e Natureza, Uberlandia, v. 20, jun. 2008, p.113-123.

MURATA, A.T.; FRANÇA, E.T.G. Impacto Ambiental e a saúde causada pela utilização de sacolas plásticas. Anais do $2^{\circ}$ Simpósio Brasileiro de saúde e ambiente. De 19 a 23 de outubro, em Belo Horizonte/ MG. P. 2-8 Disponível em:< http://www.sibsa.com.br/resources/anais/4/1406849048 ARQUIVO Afonso Mu rata.pdf > Acesso em: 10 de mai. 2019

P.F.C., BRAGA, R. (orgs.) Perspectivas de gestão ambiental em cidades médias. Rio Claro: Lab. Planejamento Municipal/Deplan/IGCE-UNESP, 2001.

RIBEIRO, T.F.; LIMA, S.C. Coleta seletiva de lixo domiciliar - Estudos de casos. Caminhos de Geografia. Vol. 1(2), 2000. P. 50-69. Disponível em:< file:///C:/Users/HP/Desktop/15253-Texto\%20do\%20artigo-57833-1-10-

20060313.pdf > Acesso em:

PLANO MUNICIPAL DE SANEAMENTO BÁSICO. Município de SérioRS<disponível em: http://www.cipaeg8.rs.gov.br/saneamentobasico/municipio/8> Acesso em 03 de maio de 2019

SEGURA, D.S.B. Educação Ambiental na escola pública: da curiosidade ingênua à consciência crítica. São Paulo: Anna Blume: Fapesp, 2001. 
SILVA, A.A.D. Direitos Humanos e o Meio Ambiente: a importância da preservação ambiental para a permanência da vida na terra. Artigos.com, 2010. Disponível em:< http://www.artigos.com/artigos-academicos/8348-direitoshumanos-e-o-meio-ambiente-a-importancia-da-preservacao-ambiental-para-apermanencia-da-vida-na-terra>. Acesso em 03 de mai. de 2019.

SILVA, M. S. F. O sistema de gerenciamento dos resíduos sólidos domiciliares em Aquidauana/MS. Dissertação (Mestrado em Geografia) UFMS/CPAQ/DGC, Aquidauana - MS, 2005. Disponível em: $<$ http://www.dominiopublico.gov.br/pesquisa/DetalheObraForm.do?select action $=\&$ co obra=99479 > Acesso em 10 de mai.2019.

SIMONETTO, E.. O; BORENSTEIN, D. SCOLDSS - Sistema de Apoio à Decisão Aplicado ao Planejamento e Distribuição da Coleta Seletiva de Resíduos Sólidos. In: XXIV ENCONTRO NACIONAL DE ENGENHARIA DE PRODUÇÃO, 03 a 05 de novembro. Anais... Florianópolis, 2004. P. 5229- 5236. Disponível em: $<$ http://www.abepro.org.br/biblioteca/enegep2004 enegep1004 0065.pdf> Aceso em 12 de mai. de 2019.

SOARES, L. G. C.; SALGUEIRO, A. A.; GAZINEU, M. H. P. Educação Ambiental aplicada aos resíduos sólidos na cidade de Olinda, Pernambuco - um estudo de caso. Revista Ciências \& Tecnologia. N 1, P. 01-09, julho-dezembro, 2007. Disponível em: < http://web-resol.org/textos/artigo5.pdf>. Acesso em $10 \mathrm{de}$ mai.2019.

TEIXEIRA, B.A.N. Gestão dos resíduos sólidos: desafio para as cidades. In: Carvalho, instituto brasileiro de geografia e estatística - IBGE. Ministério do planejamento, orçamento e gestão. Pesquisa Nacional de Saneamento Básico. (PSNB, 2008)

TENERELLI, A.; SILVA, D. G. F.; PAIVA, E. C. C. A educação e sua contribuição na garantia de sustentabilidade no processo de desenvolvimento. In: SILVA, C. L. da (Org.). Desenvolvimento sustentável: um modelo analítico integrado e adaptativo. Petrópolis, RJ: Vozes, p. 103-121, 2006.

VELLOSO, M.P. Os restos na história: percepções sobre resíduos. Ciência \& saúde coletiva (ABRASCO) SciELO - Scientific Electronic Library Online. Rio de Janeiro, vol.13, n. 6. P 1953-1964, 2007. 